\title{
LA TRANSICIÓN POSTMODERNA DERECHO Y POLÍTICA
}

\section{INTRODUCCIÓN}

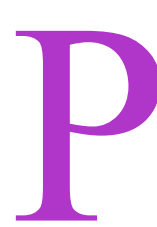

robablemente los historiadores del futuro describirán el siglo XX como un siglo desdichado. Aunque su andrógino padre, el siglo XIX, lo educó para ser un niño prodigio, éste se reveló pronto como un niño frágil y enfermizo. Cuando cumplió catorce años cayó seriamente enfermo, de una enfermedad que, como la tuberculosis o la sífilis de ese período, necesitaba un largo tiempo de tratamiento y de hecho nunca se curó completamente. Cuando cumplió treinta y nueve años tuvo una recaída y contrajo una enfermedad todavía más grave, lo que le impidió disfrutar de la vida con toda la energía que normalmente se tiene a una edad mediana. Aunque transcurridos seis años se le consideró clínicamente curado siempre ha tenido desde entonces una salud débil, con el temor a una tercera recaída grave, que con toda probabilidad esta vez sería fatal.

Mucho más pacientemente que Saint-Simon (1977:212) quien ya en 1819 pensó que era demasiado tarde para que el siglo XIX desechara la herencia del XVIII y asumiera su propio carácter, nosotros venimos esperando el significado del siglo XX. En un libro titulado precisamente The Meaning of the Twentieth Century, Kenet Boulding se conformó con caracterizar nuestro siglo, de un modo bastante vago, como el período medio de la segunda gran transición en la historia de la humanidad (Boulding 1964:1). Más recientemente, Ernest Gellner ha rechazado que la versión de la historia del siglo XX «no haya sido formulada filosóficamente con propiedad» (1986:93). Yo mismo escribí que el siglo XX corría el riesgo de no comenzar nunca, esto es, de no comenzar antes de terminar (Santos 1987a:6). Preocupaciones de carácter similar se han mantenido en varias conferencias sobre la valoración del siglo XX, organizadas en todos los lugares en los últimos años, con el resultado de que muchas de estas valoraciones 
han sido realizadas, de hecho, como apreciaciones del siglo XIX y no del XX como pretendían ser.

Sin embargo, en los últimos años, hay indicios de que esta biografía del siglo puede ser incompleta y de acuerdo con ello que las valoraciones y necrológicas han sido prematuras. De hecho, parece que nuestro siglo está ahora preparado para disfrutar una vida plena en sus años de madurez. Pero, ¿cuál es el significado real de tales signos?, ¿indican propósitos realistas y juicios sensibles acerca de la fuerza y debilidad para realizarlos en un breve período de tiempo, o más bien son un acceso de infantilismo senil?, ¿expresan un adecuado sentido de urgencia, o más bien un sentimiento autofrustrante del «retraso» que, de acuerdo con Harold Bloom $(1973,1988)$ envenena nuestra cultura y especialmente nuestra poesía contemporánea? Finalmente, incluso si asumimos que sus proyectos y propósitos son realistas y que vale la pena perseguirlos, ¿tendrá tiempo nuestro siglo de continuarlos y realizarlos?, o dicho de una forma más honesta y directa, ¿tendremos tiempo de llegar a ser los niños del siglo XX?

Aun cuando una de las proezas más ambiguas de nuestro siglo es haber transformado el sentido del tiempo en el sentido de la falta de tiempo, me inclino a dar una respuesta afirmativa y pronosticar que los años venideros confirmarán plenamente mi interpretación positiva de nuestra difícil situación actual. Esto es lo que trataré de demostrar en lo que sigue con cierta dosis de optimismo trágico tomada de Heidegger.

Este trabajo se desarrolla en tres partes fundamentales: en la primera parte presentaré un análisis interpretativo de la trayectoria (o trayectorias) histórica del paradigma de la modernidad y mostraré las condiciones que han contribuido a su agotamiento y las que señalan la aparición de un nuevo paradigma. En la segunda parte presentaré, a grandes rasgos, el perfil del nuevo paradigma, contrastando la teoría crítica moderna y postmoderna. En la tercera parte sugeriré algunas aplicaciones específicas del nuevo paradigma en el campo del derecho y la política. Cada una de estas partes comienza con el enunciado de una tesis fundamental seguida de una justificación.

\section{ASCENSO Y DECLIVE DEL PARADIGMA DE LA MODERNIDAD EN LAS SOCIEDADES CAPITALISTAS AVANZADAS}

La tesis fundamental que se sostiene en esta parte es la siguiente: el paradigma socio-cultural de la modernidad aparece 
antes que el modo de producción capitalista llegue a ser dominante y desaparecerá antes de que este último cese. Esta desaparición es compleja, porque es, en parte, un proceso de abandono $y$, en parte, un proceso de obsolescencia. Es abandono en la medida en que la modernidad ha cumplido algunas de sus promesas, en algunos casos incluso en exceso. Supone un proceso de obsolescencia en cuanto que la modernidad ya no es capaz de cumplir otras promesas. Tanto el exceso como el déficit de realización de las promesas históricas explica nuestra difícil situación actual que aparece, en la superficie, como un período de crisis, pero que, en un nivel más profundo, constituye un período de transición. Desde el momento en que todas las transiciones son parcialmente visibles y parcialmente ciegas, resulta imposible designar con propiedad nuestra situación actual. Probablemente esto explicaría por qué la inadecuada denominación "posmoderna» ha llegado a ser tan popular. Mas por la misma razón este nombre es auténtico en su inadecuación.

En lo que sigue ofreceré una justificación de esta tesis. El paradigma de la modernidad es muy rico y complejo, tan capaz de una inmensa variabilidad como propenso a desarrollos contradictorios. Basado en dos pilares, el de la regulación y el de la emancipación, cada uno de ellos constituido por tres principios o lógicas. El pilar de la regulación está constituido por el principio del Estado, formulado de manera destacada por Hobbes; el principio del mercado, desarrollado en particular por Locke y Adam Smith, y el principio de la comunidad que inspira la teoría social y política de Rousseau. El pilar de la emancipación está constituido por las tres lógicas de racionalidad tal como las identifica Weber: la racionalidad estético-expresiva de las artes y la literatura, la racionalidad cognitiva-instrumental de la ciencia y la tecnología y la racionalidad práctica-moral de la ética y el Estado de derecho.

El paradigma de la modernidad es un proyecto ambicioso y revolucionario, pero es también internamente contradictorio. Por un lado, la amplitud de sus exigencias abre un extenso horizonte para la innovación social y cultural; por otro lado, la complejidad de sus elementos constitutivos hace que el exceso de satisfacción de algunas de sus promesas así como el déficit de realización de otras sea difícilmente evitable. Tal exceso y tal déficit están inscritos en la matriz de este paradigma. El paradigma de la modernidad aspira a un desarrollo armónico y recíproco tanto del pilar de la regulación como del de la emancipación, así como a la traducción no distorsionada de tal desarrollo en la plena racionalización de la vida personal y colectiva. Este 
doble vínculo -de un pilar a otro y ambos a la praxis social- asegurará la armonización de valores sociales potencialmente incompatibles, como los de justicia y autonomía, solidaridad e identidad, igualdad y libertad.

Si gozáramos de la facultad de percibir los eventos antes de que ocurrieran efectivamente, nos sería fácil predecir que la arrogancia de tal objetivo, que va más allá de sus fuerzas, comporta en sí la semilla de la frustración: promesas sin cumplir y déficits irremediables. Cada pilar, en cuanto está basado en principios abstractos, tiende a maximizar su carga potencial, bien sea la maximización de la regulación o la maximización de la emancipación, de ese modo hace problemático el éxito de cualquier estrategia de compromisos pragmáticos entre ellos. Además, cada pilar consiste en principios independientes y funcionalmente diferenciados, cada uno de los cuales tiende a desarrollar una vocación maximalista, constituyendo, por lo que se refiere a la regulación, la maximalización del Estado, la maximización del mercado o de la comunidad; y, por lo que respecta a la emancipación, estetificación, cientificación o juridificación de la praxis social.

El paradigma de la modernidad emerge como un proyecto socio-cultural entre el siglo XVI y el final del siglo XVIII. Sólo al final del siglo XVIII comienza verdaderamente la prueba de su puesta en práctica, y este momento coincide con la aparición del capitalismo como el modo de producción dominante en las sociedades capitalistas avanzadas de hoy. Desde entonces, el paradigma de la modernidad está vinculado al desarrollo del capitalismo. Siguiendo la tradición alemana originada en Hilferding (1981), desarrollada por Offe (1985) y otros (Winckler, 1974) y aceptada, en la actualidad, por los científicos sociales ingleses (Lash y Urry, 1987), distingo tres períodos en esta evolución ${ }^{1}$. El primer período, la fase del capitalismo liberal, cubre el siglo XIX en su totalidad, aun cuando las últimas tres décadas tienen un carácter de transición, el segundo período, el período del capitalismo organizado, comienza al final del siglo y alcanza su pleno desarrollo en el período de entre guerras y en las dos décadas que siguieron a la guerra; finalmente, el tercer período, el período del capitalismo desorganizado, comienza a finales de los sesenta y todavía estamos en él.

No es mi intención aquí ofrecer una descripción completa de cada período, sino más bien mencionar aquellas características

\footnotetext{
${ }^{1}$ Para la caracterización de los tres períodos he seguido muy de cerca a Lash y Urry (1987).
} 
que posibilitan trazar la trayectoria del paradigma de la modernidad a través de los tres períodos. Mi argumento es que el primer período ya muestra que el proyecto socio-cultural de la modernidad era demasiado ambicioso e internamente contradictorio. El segundo período cumple algunas de las promesas de la modernidad (a veces incluso en exceso), pero no logra satisfacer otras, mientras intenta, en aras de una hegemonía de la política, minimizar el ámbito de sus fracasos y hacerlos invisibles social y simbólicamente. El tercer período representa la conciencia de una triple propuesta: en primer lugar, todo lo que la modernidad ha realizado no es reversible y, en la medida en que no es excesivo, debe ser defendido, pero sólo puede ser defendido con éxito en términos posmodernos; en segundo lugar, las promesas incumplidas permanecerán mientras el paradigma de la modernidad sea el dominante; finalmente, este déficit, además de ser irreversible, es mucho mayor de lo que el segundo período estaba dispuesto a admitir.

De este modo, intentaré mostrar que, conforme nos desplazamos del primer período al segundo y al tercero, el paradigma de la modernidad reduce el alcance de sus logros al mismo tiempo que los intensifica, como si estuviera animado por un efecto de rayo láser. Tal proceso de concentración/exclusión está simbolizado adecuadamente en las secuencias históricas y semánticas de tres conceptos, todos ellos arraigados en lo moderno: modernidad, modernismo, modernización ${ }^{2}$.

\section{El primer periodo}

Lo fascinante del siglo XIX es que en él las contradicciones internas del proyecto de la modernidad explosionan con gran violencia. Quiero decir, las contradicciones entre solidaridad e identidad, entre justicia y autonomía, entre igualdad y libertad. En la medida en que estas contradicciones explosionan sin mediaciones, las tendencias hacia la reducción del alcance del proyecto y la aspiración a la globalidad subyacente -es decir, la ambición de transformar radicalmente la realidad social- pueden ser vistas claramente en cada uno de los principios o lógicas del pilar de la regulación y el de la emancipación. En cuanto se descompone el pilar de la regulación, la idea de un desarrollo equilibrado y combinado de los principios del Estado, del mercado

${ }^{2}$ Existen paralelismos notables entre esta secuencia y esta otra: razón, racionalismo, racionalización. 
y de la comunidad -que contrariamente a lo que comúnmente se sostiene fue central para la filosofía política del siglo XVIII de Adam Smith y de la Ilustración Escocesa (Viner, 1927; Billet, 1975; Santos, 1985: 302 ff)- se produce un vacío ideológico en el que se dieron tres fenómenos. Primero, el desarrollo sin precedentes del principio del mercado, como se muestra en la primera oleada de industrialización, en la expansión de las ciudades comerciales, y en la aparición de nuevas ciudades industriales. Segundo, la atrofia casi absoluta del principio de la comunidad. La comunidad, que para Rousseau era una comunidad concreta de gente por cuanto la soberanía popular pertenecía en términos reales a la gente, se reduce a una estructura dualista compuesta por dos elementos igualmente abstractos: la sociedad civil, entendida como una agregación competitiva de intereses particulares y el individuo, entendido formalmente como ciudadano libre e igual. El tercer fenómeno está constituido por el desarrollo ambiguo del principio del Estado bajo el impacto de los dos primeros fenómenos, así como por el enfrentamiento con las exigencias contradictorias del laissez-faire, que, como bien señala Dicey, implican la idea de un Estado mínimo y la idea de un Estado máximo (Dicey, 1984: 306).

El pilar de la emancipación refleja, incluso con gran claridad, las tensiones convulsivas en ebullición en el interior del paradigma de la modernidad. La reducción tendencial, esto es, la tendencia hacia la exclusión y la concentración, tiene lugar en el pilar de la emancipación a través del proceso de la diferenciación funcional tal como ha sido analizado por Weber. En cuanto este proceso despliega la articulación entre las tres lógicas se hace más complejo y su interpretación en el Lebenswelt es menos probable. Esto puede apreciarse, en el nivel de la racionalidad estético-expresiva, en el elitismo creciente del movimiento romántico; en el nivel de la racionalidad cognitiva-instrumental, en el progreso espectacular de las ciencias y en su conversión gradual en una fuerza de producción, entre otras: y finalmente, en el nivel de la racionalidad moral-práctica, en la microética liberal (esto es, la responsabilidad moral exclusiva del individuo), en el formalismo legalista de la pandectística alemana empujada por el movimiento codificador del que el Código de Napoleón de 1804 sigue siendo el máximo exponente.

Sin embargo, desde mi punto de vista, el pilar de la emancipación es también en este período la matriz organizativa del fenómeno social y cultural que, a través de formas marginales o desviadas, da a la vida la aspiración de una transformación global y radical de la praxis social inscrita en el paradigma de la 
modernidad. He elegido tres de estos fenómenos, uno del ámbito de la racionalidad moral-práctica y dos del ámbito de la racionalidad estético-expresiva. El primero de ellos consiste en la construcción intelectual y social de los proyectos socialistas radicales y los movimientos tanto del así llamado del socialismo utópico o del denominado socialismo científico. Todos estos proyectos y movimientos apuntan hacia una realización completa y armónica en este mundo (incluso si este es el falansterio) de los ideales de igualdad y libertad, solidaridad y subjetividad constitutivos de la modernidad. Los otros dos fenómenos son el idealismo romántico y la gran novela realista. No estoy interesado en este momento en contrastar, como hace Gouldner (1970: 115), el pensamiento clásico y romántico, sino simplemente en mostrar que a través de una forma elitista y a veces conscientemente regresiva, el idealismo romántico representa una visión utópica de la realización plena de la subjetividad. El idealismo romántico une el paradigma de la modernidad a partir de su inquietud por la totalidad, por los orígenes y por lo vernáculo, frente al atomismo, la alienación e instrumentalización de la vida moderna, y por situar lo estético y la poesía en el centro de la integración social, el idealismo romántico que compendia la denuncia de y la resistencia a la tendencia hacia la exclusión y concentración en la puesta en práctica del paradigma social de la modernidad ${ }^{3}$. Por otra parte, la gran novela realista da testimonio de una clase -la burguesía- que fracasa en aprovechar la oportunidad de llegar a ser la clase universal y producir una transformación social radical $^{4}$, la misma oportunidad que Hegel había previsto para la burocracia y Marx para la clase obrera.

En suma, el período del capitalismo liberal pone en movimiento el proceso social de exclusión y concentración pero, en cuanto las contradicciones del paradigma explosionan sin mediación,

3 Vid. Brunkhorst para quien «el modernismo romántico se mueve, de un modo desconcertadamente cercano a la fundamental oposición conservadora o reaccionaria a la cultura moderna y a su racionalismo utópico» (1987: 409). De un modo similar, de acuerdo con Gouldner, «el potencial revolucionario del Romanticismo derivaba, en parte, del hecho de que aunque básicamente fuera una crítica de la industrialización, también podría haber sido utilizado como crítica del capitalismo y su cultura» (1970: 115).

${ }^{4}$ Según Lukács, «la categoría central y el criterio de la literatura realista constituye el tipo, una peculiar síntesis que une lo general y lo particular, tanto en caracteres como en estructuras» (1972: 5). De ahí su definición de realismo: «Una concepción dialéctica correcta de las relaciones entre ser y consciencia» (1972: 119). Vid., también, Auerbach (1968, 454 ff) y Swingewood (1975: Cap. III). 
todavía es posible en este período formular y activar, incluso de una forma marginal o desviada, la vocación de globalidad y radicalidad del paradigma, por tanto rechazar la aceptación de la irreversibilidad del déficit en el cumplimiento de las promesas.

\section{El segundo período}

El período del capitalismo organizado es ciertamente una edad positiva en el sentido comteano. Como haría, de acuerdo con Comte, un adulto razonable y maduro comienza por distinguir en el paradigma de la modernidad entre aquellas promesas que pueden ser realizadas en una sociedad capitalista dinámica y aquellas que no pueden serlo. En ese sentido, se concentra en la primera e intenta, a través de los medios hegemónicos de socialización e inculturación, eliminar la segunda del universo simbólico de la praxis social y cultural. En otras palabras, este período comienza por reconocer la idea de que el déficit de las promesas incumplidas es tanto inevitable como irreversible y por tanto hay que eliminar la idea del déficit en sí. Esta transformación ideológica se traduce en el tránsito del concepto -límite- de modernidad al concepto más reducido de modernismo.

El proceso de exclusión y concentración puede estar tanto en el pilar de la regulación como en el de la emancipación. En lo relativo a la regulación, el principio del mercado continúa la expansión espectacular iniciada en el primer período, emprendiendo nuevas formas económicas e institucionales: la concentración y centralización de la industria, capital bancario y mercantil; incremento de la regulación de los mercados; proliferación de carteles; y separación de los propietarios legales del control económico. Respecto al principio de la comunidad, el desarrollo capitalista y la expansión de la clase trabajadora que ello implica, emparejadas con la extensión del sufragio, dan lugar a cierta rematerialización de la comunidad ejemplificada en la aparición de prácticas de clase y su traducción en políticas de clase. Los sindicatos y los partidos obreros entran en el espacio político que hasta entonces estaba ocupado exclusivamente por los partidos oligárquicos y las organizaciones burguesas. El principio del Estado sufre el impacto de estos cambios y al mismo tiempo llega a ser un factor autónomo y activo en su intensificación y orientación. El Estado incrementa sus vínculos tanto con el mercado a través de una interpretación cada vez más creciente entre las burocracias estatales y los grandes monopolios y con la comunidad 
a través de la incorporación política de amplios sectores de la clase trabajadora, incrementando la intervención del Estado en las formas del consumo colectivo, en sanidad y educación, en el espacio empresarial y en la legislación social; en otros términos, a través del desarrollo del Estado del bienestar.

Estas transformaciones suponen una profunda redefinición del paradigma de la modernidad, por lo cual los grados o tipos de solidaridad, justicia e igualdad son elegidos en virtud de su compatibilidad con los grados o tipos de autonomía, identidad y libertad que son juzgados como necesarios en una sociedad capitalista y viceversa. La reformulación conduce a la aparición de dos promesas «realistas» que serán satisfechas en gran medida durante este período: la promesa de una más justa distribución de los recursos materiales y la promesa de una mayor democratización del sistema político. El cumplimiento de la primera promesa se hace compatible con la continuación de una sociedad de clases, mientras la realización de la segunda se hace compatible con la continuación de una clase política burguesa. A través de una política de hegemonía es cuando es posible transformar esta particular forma de compatibilidad, que, de hecho, es una entre otras muchas, en la única forma legítima, e incluso, quizás, en la única imaginable. Tal conversión se advierte tanto en la gradual pero constante marginación de los partidos comunistas como en la transformación social-demócrata de los partidos socialistas.

En este segundo período, el pilar de la emancipación experimenta transformaciones que son tan profundas como aquellas descritas respecto al pilar de la regulación y claro está, convergen con ellas. Tales transformaciones se reflejan en la transición desde la cultura de la modernidad al modernismo cultural. Por modernismo cultural entiendo una nueva racionalidad estético-expresiva que se extiende en este período a la racionalidad cognitiva-instrumental y a la racionalidad moral-práctica. El modernismo representa el clímax del proceso de concentración y exclusión que en el ámbito de la racionalidad estético-expresiva adopta la forma de la radical autonomía del arte (el arte por el arte), la oposición antagónica entre la alta cultura y la cultura popular y la supresión militante del contexto social, simbolizados por la arquitectura de la megápolis. Modernismo es, de este modo, la construcción social y cultural de «una gran división», en términos de Andreas Huyssen, y tiene razón al considerar el «ansia de contaminación» como la característica más reveladora del modernismo, el ansia de contaminación por parte de la política, la moralidad, la cultura popular y de masas (Huyssen, 1986: 
VII). En mi opinión, el mismo anhelo de contaminación puede rastrearse en las otras dos lógicas de la racionalidad. Por lo que se refiere a la racionalidad moral-práctica, tal ansia de contaminación está presente en las teorías de la representación política que, al favorecer los acuerdos verticales sobre los horizontales, conduce a la castración del pueblo ${ }^{5}$. El mismo anhelo de contaminación está presente en el desarrollo de una ciencia jurídica formalista opuesta a cualquier forma de conocimiento jurídico no profesional, que encuentra su expresión más extrema y sofisticada en la teoría pura del derecho de Kelsen (Kelsen, 1967). En la esfera de la racionalidad cognitiva-instrumental el ansia de contaminación está presente en la aparición de epistemologías positivistas diferentes, en el paradigma mertoniano del ethos científico (Merton, 1968: 604) y, sobre todo, en la ruptura epistemológica de Bachelard entre conocimiento científico y sentido común (Bachelard, 1971, 1972).

La intensidad de tales transformaciones y realizaciones constituyen el otro lado del déficit de totalidad en el que están basadas y que manejan con éxito para olvidarlo o suprimirlo a través de su dinamismo y ambición. La triunfante, brillante representación de lo cognoscible y de lo racional va pareja con la dictadura de las demarcaciones, la vigilancia inexorable de los límites y la pronta liquidación de las transgresiones. En este proceso, el pilar de la emancipación es cada vez más similar al de la regulación; de hecho, el pilar de la emancipación llega a ser la vertiente mental del pilar de la regulación, un proceso complejo que está elocuentemente representado en el concepto de hegemonía de Gramsci.

Mi argumento en la segunda parte de este trabajo se comprenderá mejor si les recuerdo, en este punto, que el proceso de concentración y exclusión que caracteriza la trayectoria del paradigma de la modernidad en el período del capitalismo organizado tuvo un tumultuoso principio, rico en incidentes que amenazaban su completo desarrollo. La revolución rusa y los movimientos históricos de vanguardia de los años veinte constituyen dos casos a este respecto. La revolución rusa fue un intento de dar credibilidad histórica a una forma nueva y radicalmente diferente de compatibilidad entre grados y tipos de solidaridad, justicia e igualdad por un lado, y grados y tipos de identidad,

${ }^{5}$ Estas fueron las tesis que Hannah Arendt consideró una vez como subyacentes a la Constitución americana y por tanto responsables de los últimos «fatídicos fracasos» a la hora de promover la política de la participación. Vid. Kateb (1987) y Dallmayr (1987). 
autonomía y libertad por otro. El intento falló tanto por causa del fracaso de la revolución en otros países capitalistas (muy especialmente de la revolución alemana de 1918) como por la pesadilla estalinista. Por lo que respecta a los movimientos de vanguardia -futurismo, surrealismo, dadaísmo, constructivismo ruso, proletcult, etc.- su característica más notable es que todos ellos intentan reconciliar arte y vida frente al canon modernista en sus diferentes formas. Es bien conocido cómo estos movimientos fueron liquidados por el fascismo o el estalinismo o fueron absorbidos gradualmente en el canon modernista. Pero su significación cultural no puede ser minimizada, como hace Habermas cuando concibe el surrealismo como un mero momento de sublimación del arte moderno, y como tal, dirigido al fracaso (1973: 118 ff). Peter Bürger (1984) acierta, de este modo, al enfatizar el significado cultural de los movimientos de vanguardia como movimientos históricos en los que, por primera vez, los artistas comprenden cómo el arte alcanza una autonomía y un estatus social que funciona en las sociedades capitalistas ${ }^{6}$. En otras palabras, su significado histórico se encuentra en su temprana denuncia del proceso de concentración y exclusión, cuyas consecuencias hoy estamos sufriendo.

\section{El tercer periodo}

El período del capitalismo desorganizado es el más difícil de analizar, simplemente porque es el período en el que vivimos, el búho de Minerva no tiene el privilegio de volar más que al atardecer, el único momento seguro de vuelo para el conocimiento, según Hegel.

Con relación al pilar de la regulación, las transformaciones más decisivas parecen haber tenido lugar por y a través del principio del mercado, y tanto es así que este principio parece haberse convertido verdaderamente en hegemónico, en el sentido de ser capaz de generar un surplus de significado que se vierte sobre el principio del Estado y el principio de la comunidad y trata de colonizarlos. El dramático crecimiento de los mercados mundiales va parejo con la aparición de sistemas de producción universales y agentes económicos (compañías multinacionales) que socavan la capacidad del Estado para regular el mercado a un

${ }^{6}$ Sobre el debate entre Habermas y Bürger vid. Schulte-Sasse (1984) y Jay (1985). 
nivel nacional. La industrialización del tercer mundo, la expansión de la subcontratación y franquicias internacionales, y la ruralización de la industria han contribuido conjuntamente a destruir la configuración espacial de la producción y reproducción en los países centrales: las regiones industriales tradicionales son descaracterizadas y desindustrializadas y en su lugar, reaparecen, como factor productivo estratégico, las dinámicas endógenas locales basadas, a menudo, en mezclas complejas de agricultura e industria, de producción familiar e industrial. La expansión extensiva del mercado corre paralela a esta expansión intensiva como atestigua la creciente diferenciación de productos y el consiguiente incremento de elecciones y particularización de gustos y también en la más profunda difusión de la información de la que resultan virtualmente infinitas oportunidades para la expansión de reproducciones de capital.

El impacto de estos cambios en el principio de la comunidad tiene un alcance amplio. La relación de salario se ha hecho más flexible y precaria, los mecanismos desarrollados de corporativismo en el segundo período (leyes laborales, tribunales industriales, negociación colectiva) pierden valor $\mathrm{y}$, los sindicatos, cuyos miembros disminuyen, pierden capacidad de negociación. El incremento de la diferenciación interna de la clase trabajadora industrial y la dramática expansión de las clases de servicios han contribuido a descaracterizar a las prácticas de clase y a impedir su fácil transformación en políticas de clase. Como resultado de ello, los tradicionales partidos obreros de clase suavizan el contenido ideológico de sus programas y se vuelven partidos «a la caza del voto».

El principio del Estado experimenta igualmente cambios suaves, como causa y efecto de estas transformaciones. A la vista de la transnacionalización de la economía, el Estado parece, en ocasiones, haber convertido en casi obsoleta la unidad de análisis y haber perdido la capacidad y la voluntad política de regular la producción y la reproducción social. Al convertirse, pues, en más débil externamente y menos eficiente internamente, el Estado ha llegado a ser, paradójicamente, más autoritario, actuando a través de una miríada de burocracias mal integradas, cada una de las cuales ejerce su propio microdespotismo frente a la creciente falta de poder político de los ciudadanos incompetentes.

La trayectoria de estas tres lógicas de la emancipación moderna en el período del capitalismo desorganizado está mejor caracterizada por la construcción social y cultural de un sentido de déficits irreparables y un sentido de incontrolables excesos que conjuntamente llevan a un síndrome de agotamiento y bloqueo 
global. Es muy notable el supuesto de la racionalidad cognitiva-instrumental de la ciencia y la tecnología. El compromiso de la ciencia con el complejo industrial-militar, la catástrofe ecológica, la amenaza nuclear, la destrucción de la capa de ozono, la aparición de la ingeniería biotecnológica y genética, todos estos fenómenos señalan la idea de que la promesa del progreso científico inscrita en el paradigma de la modernidad ha sido cumplida en exceso y que esta excesiva realización conlleva un déficit inestable de significado. Tal como predijo Rousseau con una desesperante previsión nos hemos dejado esclavizar por las herramientas inventadas por Bacon y Descartes para nuestra liberación (Rousseau, 1971: 52).

En la esfera de la racionalidad estético-expresiva el déficit de sentido asume la forma de la irrelevancia y domesticación. El arte moderno parece incapaz de resistir la comercialización de su singularidad o el desenfado con el que es contemplado. A pesar de lo valiosas que sean las razones de Adorno (1981) para excluir el arte moderno de un mundo equilibrado y situarlo en lo más alto o en lo más profundo, la tarea parece hoy bastante inverosímil, si no absurda: por un lado, la elevación a lo más alto es imposible en una época en la que proliferan los infinitos, incluso si son malos infinitos en el sentido hegeliano, todos ellos están forzando por los pelos las diferencias artísticas para llegar a eliminar las diferencias; por un lado, ahondar en la profundidad parece igualmente inverosímil, como una tarea de Sísifo en medio de las profundas superficialidades yuxtapuestas interminablemente, como una red rizomática de significado, en el sentido de Deleuze. La conciencia sumamente peligrosa de este impás y la pronta denuncia de agotamiento y bloqueo global en este ámbito de la lógica emancipatoria explica por qué la primera cara del paradigma emergente de la posmodernidad ha sido la estético-expresiva, como mostraré más adelante.

Finalmente, en el ámbito de la racionalidad moral-práctica, el sentido de agotamiento y de bloqueo global se ha expresado fundamentalmente de dos formas interconectadas ${ }^{7}$. En el primer período la revolución y la reforma social ocuparon por igual posiciones fuertes y rivales en el universo simbólico de aquellos grupos interesados en la emancipación y transformación social. Como el segundo período puso de relieve en las sociedades capitalistas avanzadas, la reforma social ganó una posición hegemónica

${ }^{7}$ Un profundo análisis del sentido de agotamiento y bloqueo global en las sociedades capitalistas avanzadas puede leerse en Offe (1987). 
y el concepto de revolución se escondió bajo la alfombra del pensamiento social y político. La reforma social significó básicamente una transformación pacífica e incompleta por medio de leyes abstractas y universales promulgadas por el Estado. En el tercer período los méritos de esta solución han sido cuestionados. La juridificación o hiperlegalización de la realidad social produjo relaciones sociales estandardizadas, es decir, produjo hábitos sociales unidimensionales de masa, y el empobrecimiento social de las clases populares hizo posible que fuera realizado, a través de la transformación de ciudadanos autónomos en clientes o incluso en víctimas de los estados burocráticos cada vez más autoritarios ${ }^{8}$.

En relación con esto se produce un segundo signo de agotamiento y bloqueo global que presenta en sí mismo un impás ético. Tanto la ética liberal como el reformismo social están basados en una microética, en la atribución de responsabilidad moral a los individuos y a las acciones individuales. Este paradigma puede haber funcionado de un modo más o menos adecuado en el primero y en parte del segundo período, pero hoy, ante el peligro global de la aniquilación nuclear y la catástrofe ecológica, se ha creado por primera vez en la historia una situación en la que, como señala Karl-Otto Apel, «de cara a un peligro común, hombres y mujeres están llamados a asumir una responsabilidad moral común» (1984: 250). El impás reside en el hecho de que mientras la microética es inadecuada definitivamente para orientar esta nueva situación, no ha sido aún reemplazada por una macroética capaz de «organizar la responsabilidad de la humanidad por las consecuencias (y efectos colaterales) de sus acciones colectivas a una escala planetaria» (Apel, 1984: 250).

El agotamiento y el bloqueo global de las lógicas de la emancipación y la incapacidad de cualquiera de los principios de la regulación para asegurar una compatibilidad estable entre exigencias y promesas contradictorias, crea un contexto social y cultural en el que coexiste desregulación, contractualización y convencionalidad dentro de cada uno de los sectores de la vida social, como recientemente ha subrayado Offe, con un alto nivel de rigidez e inflexibilidad en el nivel global (Offe, 1987). Todo parece posible en el arte y la ciencia, en la religión y la ética, pero, por otro lado, nada parece ser posible en el nivel de la

${ }^{8}$ Sobre esto, una fuerte afirmación de Moscovici: «A comienzo de siglo estábamos convencidos de que las masas triunfarían, mientras casi al final de él somos prisioneros de los líderes» (1985: 1). 
sociedad como conjunto ${ }^{9}$. Las sociedades capitalistas avanzadas parecen condenadas a sufrir la excesiva realización de las promesas de la modernidad y a olvidar o reprimir el déficit de las promesas incumplidas.

Así, como Max Weber mostró, mejor que ningún otro autor, las antinomias del proyecto de la modernidad en el primero y segundo período del capitalismo, también Habermas ha mostrado las antinomias del tercer período. Como cuestión de hecho, coincidimos con él en que el proyecto de la modernidad es un proyecto inacabado (Habermas, 1985). Pero mientras Habermas entiende que este proyecto puede ser completado en términos subparadigmáticos, es decir, recurriendo a los instrumentos culturales, sociales y políticos desarrollados por la modernidad, en mi opinión, lo que haya de completarse sólo puede serlo en términos y con instrumentos del nuevo paradigma.

\section{TOPOI PARA EL NUEVO PARADIGMA}

La principal tesis de esta parte es la siguiente: la idea moderna de una racionalidad global de la vida social y personal acaba por desintegrarse en una multitud de mini-racionalidades al servicio de una racionalidad global incontrolable e inexplicable. Es posible reinventar las mini-racionalidades de tal forma que dejen de ser partes de una totalidad para convertirse más bien en totalidades presentes en muchas partes. Esta es la tarea de la teoría crítica postmoderna.

En lo que sigue proporcionaré la justificación para esta tesis. La descripción interpretativa del tercer período, el período del capitalismo desorganizado, es sólo una parte del cuadro. Como he mencionado al principio, en este período han ido acumulándose los signos del comienzo de un nuevo paradigma que, por las razones entonces indicadas, puede ser calificado como el paradigma de la postmodernidad. Con relación a las lógicas de la emancipación, desde el final de los sesenta y mitad de los setenta, y especialmente en los Estados Unidos, la racionalidad estético-expresiva de las artes y la literatura ha emprendido una crítica

${ }^{9} \mathrm{Cfr}$. la afirmación de Offe sobre nuestra condición contemporánea: «Por un lado, todos los factores cercanos de nuestra vida social, económica y política son electivos de forma contingente y están sujetos a cambio, mientras por otro lado, las premisas institucionales y estructurales sobre las que se mueve la contingencia son, simultáneamente, alejadas del horizonte político, así como de la elección intelectual» (1987: 8). 
radical al canon modernista, esto es, la crítica de la modernización, estandardización y funcionalismo; una crítica del estilo internacional, del expresionismo abstracto, de la música en serie y del modernismo clásico literario. Tal crítica, como señala correctamente Huyssen, ya está presente en la generación beat de mitad de los cincuenta (Huyssen, 1986: 186). Una vez percibido el agotamiento del canon modernista, se busca un nuevo comienzo, en arquitectura, así como en pintura, teatro, cine y música. La característica fundamental de esta nueva búsqueda es el deseo de cruzar los límites entre la alta y la baja cultura, mezclar los códigos y rescatar el contexto social y la lengua local, valorar la Gemeinschaft, sobre la Gesellschaft, en otras palabras, restablecer la vocación crítica y antagonista del arte, no negando el mundo, como ha sostenido Adorno, sino por el contrario, afirmando el mundo y buceando profundamente en la realidad.

En el campo de la racionalidad cognitiva-instrumental de las ciencias y la tecnología, la crisis epistemológica de la ciencia moderna se remonta a principio del siglo y desde entonces se ha hecho más profunda y más extensa. Los momentos más importantes de este proceso son: la teoría de la relatividad de Einstein (Reichenbach, 1970), el principio de incertidumbre de Heisenberg, el principio de complementariedad de Bohr (Heisenberg, 1971), el teorema de Gödel (Ladrière, 1967: 312; Jones, 1982: 158; Parain-Vial, 1983: 52; Briggs y Peat, 1985: 22), la teoría de las catástrofes de Thom (1985) y, más recientemente, la teoría de las estructuras disipativas de Prigogine $(1979,1980,1981)$, la teoría sinergética de Haken (1977, 1985), el concepto de hiperciclo de Eigen (1979), la noción de autopoiesis de Maturana y Varela (1973, 1975), la teoría del orden implicado de David Bohm (1984) y la teoría de la matriz-S de Geoffrey Chew y la filosofía de bootstrap que la subyace (1968, 1970. Capra, 1979). Todas estas tendencias señalan una nueva ciencia. Sus diversos nombres -la nueva alianza de Prigogine (1979), la nueva física de Fritjof Capra o el Tao de la física (1976, 1983), el paradigma de la autoorganización de Jantsch (1980, 1981), el espíritu inmanente de Bateson (1985), el orden implicado de Bohm (1984)- son los posibles nombres de una ciencia postmoderna.

Finalmente, por lo que respecta a la racionalidad moral-práctica de la ética y el derecho los límites de la microética liberal y la forma jurídica conectada a ella ya han sido expuestas. Esta forma ética y jurídica es totalmente inadecuada para orientar algunos de los problemas más serios de nuestra época, desde el de Chernobyl al del SIDA. El punto en cuestión es que un 
nuevo iusnaturalismo está apareciendo, no como una construcción abstracta e intersticial, sino como la configuración simbólica de las nuevas luchas sociales que discutiremos más adelante.

En el nivel de los principios de regulación, la identificación de los signos de la postmodernidad es particularmente difícil. Lo que desde un ángulo parece ser nuevo y discontinuo respecto al pasado, cuando se ve desde otro ángulo es, realmente, un progreso ininterrumpido hasta el presente. El principio del mercado es el más ambiguo. De un lado, la expansión intensiva y extensiva del mercado hace cada vez más difícil el éxito de cualquier opción social o cultural, antagonista, alternativa y desinteresada, en la medida en que hay un peligro inminente de que sea encerrada, absorbida, domesticada y convertida en otra esfera de la producción capitalista. Por otro lado, en la época de la realidad televisiva y de información, las oportunidades para un consumo más democrático e incluso una producción del saber son inmensas. La creciente competencia social y cultural que cabe esperar de aquí puede, en efecto, materializarse si el dramático crecimiento de la productividad de los últimos años continúa. La reducción de la jornada de trabajo, cada vez más importante en las controversias laborales, ampliará el tiempo libre y la producción será desplazada por el consumo; en este caso la prioridad de la producción, básica para el paradigma de la modernidad y presente tanto en la teoría social como en la arquitectura modernista, se derrumbará (Jencks, 1987: 11 ff; Huyssen, 1986: 187).

Por lo que respecta al principio de la comunidad, la relativa debilidad de prácticas de clase y políticas de clase han sido compensadas por la aparición de nuevos espacios antagonistas que proponen nuevos programas sociopostmaterialistas y políticas (paz, ecología, igualdad sexual y racial), que han de ser realizados por nuevos grupos insurgentes y movimientos sociales. En este sentido se podría decir que el siglo XX sólo comienza en el tercer período del desarrollo capitalista. En efecto, el descubrimiento de que el capitalismo produce clases y que estas clases son la organización matriz de las transformaciones sociales fue un descubrimiento del siglo XIX. El siglo XX entra en la escena histórica sólo cuando descubre que el capitalismo también produce diferencias raciales y sexuales y que éstas también pueden ser puntos nodales para las luchas sociales.

Finalmente, el principio del Estado, que en el período del capitalismo organizado funcionaba mucho más como la plataforma estructurada para la actuación, tanto del principio del mercado como del principio de la comunidad, ahora parece batirse en retirada como si sólo estuviera capacitado para un papel 
secundario frente a los otros dos principios. La retirada del estatalismo está relacionada con cambios en el sistema mundial de los Estados y especialmente con el declive del imperio americano y la reaparición de la Unión Soviética como un amplio campo de experimentación social en el que el principio del mercado y el principio de la comunidad adquieren una nueva importancia. Estas tendencias no indican necesariamente el final del estatalismo o el final de la crisis del Estado de bienestar, pero cambian el debate político de tal forma que posibilitan un lugar para un Welfare State más inteligente y particularizado, o más bien, para una articulación renovada entre el Estado del bienestar y lo que podemos llamar la sociedad del bienestar, es decir, una nueva y más polifónica conciencia comunitaria.

¿Son suficientes estos signos para sostener la aparición de un nuevo paradigma? Los criterios de verdad de las dos respuestas, una respuesta negativa y una positiva a esta cuestión, son equivalentes. Vivimos en un período de transición paradigmática, y como nos ha enseñado Koyré en su estudio sobre la revolución científica del siglo XVI, en tales períodos esta cuestión no puede ser respondida en términos de exigencias de verdad, precisamente porque los criterios que fundamentan tales exigencias están en cuestión (Koyré, 1986; Kuhn, 1970). Lo que está en cuestión no es una decisión sobre la validez de nuevos descubrimientos sino más bien la aparición o no de una nueva percepción de la realidad. De este modo, la cuestión será decidida, en última instancia, en términos de fuerza relativa -una fuerza pragmática y retórica- de los grupos que aprueben una u otra percepción global.

Este hecho tiene una implicación doble cuyo argumento propondré en lo que sigue. En primer lugar, explica la crítica de las epistemologías modernas, a las que Rorty califica como epistemologías modernas, a las que Rorty califica como epistemologías fundacionalistas (1980), y del concepto de verdad en el que están basadas, una crítica presente de diversas formas en la obra del propio Rorty, Gadamer (1965, 1983), Feyerabend (1978, 1981, 1985) y Morin (1982). En segundo lugar, da cuenta del resurgimiento de la versión de pragmatismo de James y Dewey y del renovado interés por la retórica griega y medieval, que puede remontarse a 1967, fecha de la publicación de la Nueva Retórica de Perelman (1971). Finalmente, el hecho de que en un período de transición paradigmática la cuestión de la verdad sólo puede ser resuelta en términos pragmáticos y retóricos, explica por qué todos los intentos de definir el postmodernismo con categorías abstractas han fracasado. En un sentido, tales intentos representan 
una forma moderna de capturar la postmodernidad, con redes que no sujetan al pez. Esto es cierto incluso en los más sofisticados catálogos de características de la postmodernidad, tales como el que ha propuesto Ihab Hassan, que incluye: indeterminación, fragmentación, descanonización, desinterés, falta de profundidad, lo impresentable irrepresentable, ironía, hibridización, carnavalización, actuación, participación, construccionismo e inmanencia (Hassan, 1987: 167).

En mi opinión, este y otros listados similares todavía son presentados en términos modernistas, en este sentido dejan fuera el contexto hermenéutico y existencial que debería subyacer a la combinación y concreción de estas categorías; es más, también prescinden de la fuerza pragmática y retórica que aportan para construir un nuevo modo intelectual y un nuevo sentido común. Por mi parte, preferiría contar tres breves historias, o más bien tres guiones para historias que podrían ser contadas o representadas en comunidades educativas. Cada una es una historia parcial en el sentido que, de acuerdo con William James, «el mundo está lleno de historias parciales que corren paralelas unas a otras, comenzando o terminando de vez en cuando» (1969: 98). De cada historia puede extraerse un topos retórico pero el poder persuasivo o argumentativo de cada uno de ellos deriva sobre todo de la cadena retórica o la secuencia en la que está integrado.

\section{Lo conocido y lo desconocido}

La primera historia nos cuenta que el conocimiento moderno es un extraño pájaro con dos alas que no son iguales. Una de las alas, llamada complicidad, vuela bajo tocando los tejados de las oficinas del gobierno y las sedes de las empresas de negocios; la otra, llamada crítica, vuela alto, medio escondida por las nubes. No es sorprendente que tan deforme pájaro chocara con las montañas de nuestra flexibilidad. Si inspeccionamos los restos nos convenceremos de que todavía estamos vivos para recoger de los escombros los siguientes topos.

El primer tópico puede expresarse así: «No tocar. Esto es humano.» Ahora nuestra situación epistemológica se enfrenta con un dilema: la ignorancia es imperdonable pero el conocimiento a veces es insufrible. Tomemos el ejemplo de la investigación en el código genético y en la ingeniería genética. Debemos pensar razonablemente que cuánto más sepamos en este campo será más probable que los seres humanos lleguen a ser el 
producto alternativo y esencial. Si esto es así, quizás necesitamos un guardia para alzar la voz en favor del ser humano, de la misma forma que el guardia de la exposición de arte postmoderno en Kassel gritó en favor de la autonomía del arte cuando los hijos de Huyssen pasaron sus dedos sobre los rostros de uno de los trabajos de la exposición: «Nicht berühren. Das ist kunst.» («No tocar. Esto es arte.») (Huyssen, 1986: 179.)

El segundo tópico: «No es problema si es o no real, con tal de que nos sea cercano.» El conocimiento moderno en general (la ciencia moderna, tanto como el arte moderno, la ética y el derecho modernos) están basados en la representación, esto es, en la creación y el aislamiento de lo otro, llamado objeto, donde el ser, llamado sujeto, describe como ser lo que es independiente de una intervención creativa del yo. De este modo, la representación crea una distancia, cuanto mayor es la distancia, más objetivo es el conocimiento. En un reciente análisis de la pintura holandesa del siglo XVII, Susan Sontag enfatiza la forma en que los artistas combinan «la atmósfera del alejamiento con la exactitud de la pintura, la pintura de una iglesia real desde un punto de vista real, aunque nunca desde cerca» (Sontag, 1987: 125). Ciertamente, lo real y lo cercano han sido siempre antagonistas en el conocimiento moderno. El conocimiento postmoderno, a su vez, prefiere lo cercano en detrimento de lo real. Ser pragmático es aproximarse a la realidad desde lo que James llama «las últimas cosas», es decir, desde las consecuencias, cuanto más corta es la distancia entre actos y consecuencias, mayor es la precisión del juicio sobre la validez. Por otro lado, porque es retórica, el conocimiento postmoderno anhela la dimensión oral, la comunicación directa que, como muestra Walter Ong, es situacional, cercana al mundo vivo de lo humano, empatética y participativa antes que objetivamente distanciado (Ong, 1982: 36). El conocimiento postmoderno es, pues, local, pero siendo local es también total. El localismo que implica es el localismo del contexto, no el localismo de espacios estáticos y de tradiciones inmemoriales. Es un localismo internacionalista, sin un sólido genius loci, más bien como el localismo de la nueva generación de los artistas «objetivistas» americanos o más bien neoyorkinos, los «nuevos objetivistas», de acuerdo con la interpretación de Bonito Oliva sobre sus trabajos (Oliva, 1988: 62).

Finalmente, el tercer tópico: «de la afirmación a la crítica a través de las alternativas». La teoría crítica moderna se afirma a sí misma negando el mundo, confrontándolo o escapando de él pero siempre poseída por la ansiedad de contaminación. Esta postura tiene como premisas dos condiciones: el efecto de lejanía 
que produce el punto de vista de la representación del conocimiento; y la concepción de la realidad social como un presente monolítico. La primera condición ya la he criticado. Respecto a la segunda, su carácter insostenible se hace más evidente en cuanto entramos en una época caracterizada por la instantaneidad del tiempo social, de la realidad más veloz, de la experiencia televisiva, de imágenes gobernadas por estéticas de desaparición, como indicó Paul Virilio (1988: 57). Ahora parece más claro que existen generaciones de realidad en la medida en que existen generaciones de imágenes. Hay realidades que surgen como realidades testimoniales, trasplantadas o residuales. La situación existencial específica de la realidad que surge no puede ser afirmativa antes de ser crítica. ¿Cómo es posible entonces que sea afirmativa sin ser cómplice y crítica sin ser escapista? A través de la constante producción de alternativas, asumiendo el riesgo de absorción por la realidad constantemente revisada y reciclada. La teoría crítica postmoderna es positiva en este sentido, al buscar infatigablemente fragmentos genuinos de contenido en la manipulación y la dominación, para plantear el uso alternativo de creación de nuevos espacios de emancipación. Por tanto, asume el salto a la realidad en la búsqueda de un nuevo sentido común. La teoría crítica postmoderna es polifónica y agonística: frente al conocimiento crea conocimientos y frente a los conocimientos, contra-conocimientos.

\section{Lo deseable y lo posible}

El segundo guión trata de la nueva situación en la que vivimos, la discrepancia entre lo deseable y lo posible. Cuando lo deseable fue imposible cedió su puesto a Dios; cuando lo deseable fue posible cedió su puesto a la ciencia. Ahora que una parte de lo deseable es de nuevo imposible y una parte de lo posible no es ya deseable no podemos contar ni con Dios ni con la ciencia. Sólo podemos contar con nosotros mismos. Y porque todo está en nuestras manos no es sorprendente que estemos interesados de manera creciente en el lenguaje (de aquí el segundo Wittgenstein), en la persuasión y en el poder del conocimiento (de aquí Nietzsche, Foucault y la Nueva Retórica) y, finalmente, en la comunicación e interacción humana (de aquí el renacimiento del pragmatismo americano).

Para cultivar nuestros nuevos intereses, imagino un tipo de escuela en la que haya dos clases: en la primera, en la que se enseña la conciencia del exceso, aprendemos no a desear todo lo 
que es posible, precisamente porque es posible; en la segunda, en la que se enseña la conciencia de la escasez, aprendemos a desear lo imposible. Los estudiantes del postmodernismo reaccionario asistirían sólo a la primera clase; los estudiantes del postmodernismo progresivo acudirían a ambas al mismo tiempo. El objeto de la comunicación que tiene lugar en estas clases no es obtener consenso, como Habermas pretendería, sino antes bien formular nuevas necesidades radicales en formas agonísticas armonizadas, como Agnes Heller sugeriría ${ }^{10}$.

Sin embargo, esta descripción no es suficiente para distinguir la teoría crítica postmoderna de la teoría crítica moderna. Después de todo, tanto Habermas como Heller suscriben la última. Lo que distingue la teoría crítica postmoderna es que las necesidades radicales no están formuladas por una filosofía radical; más bien surgirán de la imaginación socio-estética situada en la práctica emancipatoria cotidiana. Sólo si se encastra en lo cercano, aunque se trate de un cercano nuevo y desconocido. Algunas condiciones sociales emergentes parecen señalar, en efecto, en esta dirección. Ernest Gellner en un ensayo reciente manifestaba, incluso con algunos temores, su desencanto con las tesis del desencantamiento. Como sabemos, la tesis indica que el mundo moderno del «contrato de Fausto» del poder cognitivo, tecnológico y administrativo nos impele a cambiar nuestro mundo previo, significativo y humanamente interesado por «un mundo predecible, más sumiso, pero fríamente indiferente e inhóspito» (Gellner, 1987: 153).

Esta es la bien conocida jaula de hierro a la que Weber nos ha condenado. Gellner, sin embargo, argumentaba que la jaula de hierro sólo es aplicable al período de aparición de la sociedad industrial. Hoy, cuando la semana de trabajo se ha reducido, y han disminuido las actividades que requieren el pensamiento cartesiano, hemos dejado la jaula de hierro para entrar en una jaula de goma. A mi juicio, la jaula de goma sigue siendo una jaula y seguirá siéndolo mientras lo deseable y lo posible no sean redefinidos en términos propios de la postmodernidad. La teoría crítica moderna así como la teoría de la modernización convirtieron lo deseable y lo posible en valores funcionales; la diferencia entre las dos teorías reside en la forma en la que identifican las funciones y los grupos sociales que se benefician de ellas.

Para la teoría crítica postmoderna, lo deseable y lo posible son también valores estéticos y su funcionalidad no puede separarse

\footnotetext{
${ }^{10}$ Para una comparación entre el pensamiento de Heller y de Habermas, vid. Radnoti (1987).
} 
de su belleza. En este, como en muchos otros ejemplos, el pensamiento postmoderno innova por cuotas, recuperando y reciclando formas degradadas de la modernidad. Tradicionalmente hemos considerado a Saint-Simon como el padre de la teoría de la modernización, de la idea de convertir la ciencia y la tecnología en una gran máquina de progreso, por consiguiente una sustitución gradual de la política por la administración de las cosas. Sin embargo, si observamos la forma en la que concibe el nuevo sistema político en 1819-1820, parece claro que para él, lo deseable y lo posible estuvieron constituidos de forma inseparable por la utilidad y la belleza. En esta perspectiva, la primera Cámara de los Comunes, llamada la Cámara de Invención, estaría formada por trescientos miembros, entre quienes se encontrarían doscientos ingenieros, veinticinco pintores, quince escultores y arquitectos y diez músicos. Esta cámara tendría a su cargo la presentación de proyectos públicos, los más importantes de los cuales hoy llamaríamos infraestructuras físicas. No obstante, añade «los caminos y canales que han de ser construidos no son concebidos sólo como medios que faciliten el transporte, su construcción debería plantearse para que fueran lo más agradables posibles para los que viajan» (Saint-Simon, 1975: 203). Como si temiera que esto no estuviera totalmente claro o no fuera juzgado como importante añadió una nota a pie de página: «Quinientos acres de tierra (más si lo que piensa es correcto) serán elegidos de los solares más típicos cruzados por carreteras y canales. Esta tierra será autorizada para su uso y quedarán lugares para viajar y para descansar para los habitantes de la vecindad. Cada uno de estos jardines contará con un museo de productos naturales e industriales de los distritos circundantes. Incluirán también viviendas para los artistas que deseen establecerse allí, y un cierto número de músicos podrá también permanecer allí para inspirar a los habitantes del cantón con aquella pasión cuyo desarrollo es necesario para el mayor bien de la nación» (Saint-Simon, 1975: 203).

\section{Interés y capacidad}

De acuerdo con el tercer guión, los hombres y mujeres modernos solían vivir en una ciudad fronteriza cuya transformación dinámica estaba basada en la ecuación interés = capacidad. Sin embargo, tenían un interés en el proceso de transformación que exigía también una adecuada capacidad para llevarlo a cabo. Cuanto mayor sea el interés, más importante será la capacidad. 
El pensamiento político liberal tenía como premisa la idea de que la burguesía era, entre las diferentes clases sociales, la más interesada en el desarrollo del capitalismo y, por tanto, la más capaz de llevarlo a cabo. De modo similar, la teoría marxista tenía como una de sus premisas la idea de que la clase obrera era la clase más interesada en superar el capitalismo y por consiguiente la más capaz de hacerlo. Con una elocuencia insuperable, el Manifiesto Comunista de 1848, sin duda alguna uno de los grandes textos de nuestra modernidad, vincula el papel histórico privilegiado de la clase obrera en la realización de la revolución social al hecho de que esta clase, a diferencia de otras, no tiene nada que perder excepto sus cadenas.

Los años pasaron para los hombres y mujeres modernos que se trasladaron a un hábitat euro-americano y allí la ecuación interés = capacidad parecía haberse desplomado. Incluso asumiendo que la clase obrera todavía tiene un interés en superar el capitalismo, mostraron de modo patente una carencia de capacidad para ello. Y si sostenemos, como hipótesis teórica, que esta capacidad permanece latente todavía, parece que han perdido interés en poner su capacidad en acción.

Mientras tanto, las dos últimas décadas han testificado la aparición de grupos sociales claramente interesados en las llamadas luchas postmaterialistas: la paz, la defensa del medio ambiente, la lucha contra el holocausto nuclear, la combatividad frente a la discriminación racial y sexual. Estas luchas se han enfrentado a tres problemas fundamentales. El primero puede ser formulado en términos dilemáticos: cuanto mayor es el interés (por ejemplo, el interés por la paz o la ecología respecto al interés en la igualdad sexual y racial), mayor será la dificultad de identificar el sujeto histórico más capacitado para dirigir la lucha social. El segundo problema es que la dificultad de equiparar interés y capacidad es más complicada por la dificultad de conocer de antemano cuáles de estos intereses y luchas puede realizarse con éxito en las sociedades capitalistas y cuales sólo pueden ser realizados superándola y reemplazándola por el socialismo. En el último caso, mucha gente se encuentra a sí misma en la posición contraria a la que describe el Manifiesto Comunista: tienen un gran interés en el éxito de la lucha pero al mismo tiempo sienten que tienen mucho que perder en las transformaciones que tendrán lugar. En la medida en que tales luchas puedan triunfar dentro del marco capitalista aparece un tercer problema: en el supuesto de que las luchas tengan éxito y se repartan los bienes que se supone hay que repartir, cómo evitar la devaluación social de tales bienes. En el pasado, el capitalismo 
fue capaz de devaluar tales bienes transformándolos en nuevas oportunidades, por iniciativas lucrativas o bien circunscribiéndolos a ese sector separado y segregado de la acción social, que llamamos político.

\section{POLÍTICA Y DERECHO EN LA TRANSICIÓN POSTMODERNA}

La tesis central de este análisis puede formularse como sigue: Es necesaria una nueva teoría de la subjetividad que explique el hecho de que nos encontramos en una compleja red de subjetividades que va incrementándose. Más allá de las ruinas del colectivismo social, está emergiendo el colectivismo del yo. La lucha frente a los monopolios de interpretación debe orientarse de tal forma que lleve a la proliferación de comunidades interpretativas políticas y jurídicas. El control disperso de la esfera jurídica contribuirá a descanonizar y trivializar el derecho. El fin del fetichismo legalista marcará la aparición de un nuevo minimalismo jurídico y de prácticas micro-revolucionarias.

Intentaré justificar estas tesis acudiendo a mis guiones para sostener una comprensión postmoderna y crítica del derecho y la política. El último guión (interés y capacidad) pone de relieve que ha ido incrementándose la discrepancia entre la escala de los intereses en la transformación social y la organización de capacidades para luchar por ellos. En la medida en que muchos intereses se han convertido en intereses globales, el enemigo frente al que combatir parece haberse desvanecido, lo cual, contrariamente a lo que cabría esperar, no ha facilitado la organización de quienes querían mantenerse activamente en la lucha. Esto ha agravado el impás de la teoría crítica moderna y, en particular, la teoría marxista ortodoxa, un impás que ha cristalizado en una doble reificación: la reificación del sujeto histórico y la reificación de la mediación política para el despliegue de las capacidades sociales. La aparición de la teoría crítica postmoderna tiene como premisa el abandono de esta doble reificación.

La reificación del sujeto histórico ha consistido en la concesión de un privilegio histórico a priori a la clase y a las políticas de clase, esto es, utilizando las palabras de Laclau y Mouffe, en «la idea de que la clase obrera representa el agente privilegiado en quién reside el impulso fundamental del cambio social» (Laclau, Mouffe, 1985: 177). La crítica de esta reificación ha sido expuesta brillantemente por Laclau y Mouffe. Pero, contrariamente a su punto de vista, no es ni necesario ni correcto acudir 
al extremo opuesto y concluir que la «sociedad no tiene esencia», es decir, que es imposible explicar en términos socio-teoréticos el problema de la determinación histórica (Mouzelis, 1988). En mi opinión, la tarea más importante para la teoría social hoy consiste en combinar la contingencia global con los determinismos locales, estructuras y medios concretos. Si la esencia es entendida en términos monolíticos, como el ser de la sociedad, en todas las versiones del holismo, comenzando con Durkheim, o como el del individuo, en las teorías recientes del individualismo metodológico, sólo es correcto ser antiesencialista. Pero entre la esencia entendida como una entidad ontológica monolítica y el no esencialismo de infinitas contingencias existe un espacio intermedio de puntos de vista pluralistas sobre la esencia, de una dispersión controlada de estructuras sociales ${ }^{11}$.

Por lo que se refiere a la cuestión del sujeto histórico, entiendo que en lugar de establecer una prioridad a priori o un sujeto histórico, como hace el marxismo ortodoxo, o en lugar de suavizar la cuestión del sujeto bajo la alfombra del conocimiento social, como han hecho los estructuralistas y postestructuralistas, la tarea consiste en analizar en términos concretos nuestras trayectorias históricas como sujetos en el nivel macro y biográfico. Los hombres y mujeres modernos son configuraciones o redes de diferentes subjetividades e incluso la diferenciación interna del yo es una variable histórica, como ha señalado adecuadamente A. Heller ${ }^{12}$, y entiendo que la diferenciación no es ni infinita ni caótica. Como he propuesto en otro lugar, las sociedades capitalistas contemporáneas constan de cuatro contextos estructurales a los que corresponden cuatro subjetividades estructurales: al ámbito doméstico corresponde la subjetividad de la familia, al ámbito de la producción o del trabajo corresponde la subjetividad de la clase; a la ciudadanía corresponde la subjetividad del individuo; y al ámbito mundial corresponde la subjetividad de la nación (Santos, 1985).

Esta no es la ocasión para dar una explicación exhaustiva de este esquema de análisis. Sólo habría que retener que los hombres y las mujeres modernos son configuraciones de cuatro subjetividades básicas. Por supuesto, también son otras subjetividades

${ }^{11}$ Mi estudio sobre los modos de producción del derecho y el poder social (1985), constituye, precisamente, un intento de presentarlos como punto de vista pluralista sobre estructuras.

${ }^{12}$ De acuerdo con Heller, «la diferenciación interna del yo es variable en sí misma..., por otra parte, no sólo es histórica, sino también una variable "personal”» (1987: 15). 
(por ejemplo, hombre/mujer, blanco/negro), pero todas ellas están fundadas en las cuatro subjetividades básicas. Por otro lado, la configuración específica de las diversas subjetividades varía en relación con diferentes condiciones históricas, con diferentes períodos de nuestra vida e incluso en relación con circunstancias o rutinas cotidianas. Asistimos a las reuniones del colegio de nuestros hijos como miembros de una familia, trabajamos durante el día como miembros de una clase o de una fracción de clase, vamos de compras o leemos el periódico como individuos, asistimos a un partido de nuestro equipo nacional como nacionales. En todas esas ocasiones o situaciones somos las cuatro, y quizá incluso otras subjetividades más al mismo tiempo, pero como las ocasiones y situaciones varían, una subjetividad básica diferente tiene el privilegio de organizar la configuración específica de las subjetividades que explican nuestro comportamiento y actitudes. En este sentido, la construcción social y científica de la teoría crítica postmoderna está basada en la idea de que entre las ruinas del colectivismo social está emergiendo el colectivismo del yo.

La segunda reificación de la teoría crítica moderna, la reificación de la mediación política para el despliegue de las capacidades sociales, que consiste en la reificación del Estado. En efecto, tal proceso es central a la teoría política liberal, que la teoría crítica toma prestada, y consiste en reducir la política a un sector separado de la acción social, entendida esta última como acción de $\mathrm{y} / \mathrm{o}$ a través del Estado. Esta reificación adquirió gran importancia en el período del capitalismo organizado y encontró su expresión más completa en la forma política del Estado de bienestar.

En la actualidad, la crisis de esta concepción es aparente. La teoría crítica postmoderna está basada en dos ideas. Primera, la hiperpolitización del Estado que es la otra cara de la despolitización de la sociedad civil. La esfera pública, confinada a un sector específico de la acción social, el ideal democrático de la política moderna que ha sido neutralizado o fuertemente limitado en su capacidad emancipatoria (Santos, 1985: 306). Segunda, la libertad no es un bien humano natural que ha sido preservado frente a la política, como exige la teoría política liberal ${ }^{13}$. Por el contrario, cuanto más amplia es la esfera política, mayor es la libertad. El fin de la política siempre significará, de una manera o de otra, el final de la libertad.

${ }^{13}$ Una crítica de la concepción liberal de la libertad como esencia prepolítica puede verse en Arendt (1963: 149). 
Basándome en estas dos ideas y siguiendo a Foucault, entiendo que hay política allí donde hay relaciones de poder. Sin embargo, también entiendo, y ahora contrariamente a Foucault, que no podemos llegar al extremo de abandonar la tarea de estructurar y graduar las formas y las relaciones de poder. Si el poder está en todas partes está aquí y ahora. En mi opinión, los cuatro contextos estructurales que he mencionado antes constituyen el lugar de las cuatro formas fundamentales de poder que circulan en nuestra sociedad (Santos, 1985: 309). Estas formas de poder son: patriarcado, que corresponde al ámbito doméstico; explotación, que corresponde al ámbito de la producción; dominación, que corresponde a la ciudadanía; y cambio desigual, que corresponde al ámbito mundial. Existen otras formas de poder pero éstas constituyen las formas básicas. Ninguna de estas formas de poder es política en sí misma. La combinación entre ellas es lo que las hace políticas, cada una es política en su propia forma. De todas estas formas de poder sólo una, la dominación, es democrática, e incluso ésta lo es en un grado limitado y en un número reducido de países en los que están incluidas las sociedades capitalistas avanzadas. El objetivo político de la teoría crítica postmoderna radica en extender el ideal democrático a las demás formas de poder. El socialismo es la expansión continua e incansable y la intensificación de la práctica democrática. Este objetivo, en cuanto no se limita a sí mismo, muestra inevitablemente el límite del capitalismo, el punto en el que las relaciones sociales capitalistas bloquearán la expansión de la emancipación democrática.

La politización de las relaciones sociales, global pero no indiscriminada, marcará el final de los monopolios de la interpretación política, al mismo tiempo que asegurará que no tendrá lugar una renuncia a la interpretación, típica de las sociedades de consumo de masas. Mientras para la teoría crítica moderna la democratización radical de la vida personal y social sólo tuvo un enemigo, el monopolio de la interpretación (sea la religión, el Estado, la familia o el partido), para la teoría crítica postmoderna tiene dos enemigos igualmente fieros: los monopolios de interpretación y la renuncia a la interpretación. Para luchar contra ambos sólo hay una alternativa: la multiplicación de comunidades políticas interpretativas. Estructuradas ligeramente por las combinaciones específicas de subjetividades y de formas de poder social, tales comunidades constituyen la base social de un nuevo sentido común político, un nuevo acuerdo político basado en virtudes cívicas nuevas y viejas, en el sentido de Dewey, virtudes que no se han vertido en nosotros como flujos metafísicos 
de algún deux ex machina, sino que más bien surgen de lo familiar y lo cercano. En este sentido, Charles Jencks está en lo cierto cuando incluye entre los valores postmodernistas la idea de que «la presencia humana está de espaldas incluso cuando aparece de perfil» (Jencks, 1987: 11). La presencia humana está de espaldas pero no como una identidad irreflexiva, disuelta en tradiciones profundamente arraigadas. Nuestras raíces están permanentemente presentes, son el rizoma que prolifera en la superficie profunda y en la eternidad momentánea de nuestros encuentros significativos. Las comunidades tradicionales en las sociedades capitalistas avanzadas serían tan poco útiles para nosotros como los gremios medievales fueron para Durkheim cuando propuso la reconstrucción de los corps intermediaries (entre el Estado y el individuo), cuya carencia se explica, desde este punto de vista, por la anomía rampante en la sociedad francesa en el cambio de siglo (Durkheim, 1964: prólogo a la 2. a ed.).

La multiplicación de las comunidades políticas interpretativas representan el camino de la postmodernidad y, por tanto, el único modo razonable de defender la realización de la modernidad. Como he mencionado con anterioridad, entre tales realizaciones se encuentra una distribución más justa de los recursos económicos y una democratización significativa del sistema político, en el sentido convencional. Como ocurre con todos los procesos de transición, la transición postmoderna tiene también un lado oscuro y uno claro. El primero es que, tal como muestra la reificación de la clase y del Estado, los instrumentos modernos utilizados hasta ahora para realizar y consolidar sus promesas, es decir, las clases políticas y el Welfare State, se vuelven menos adecuados y eficientes. La proliferación de las comunidades políticas interpretativas limitarán las cuestiones políticas en dos direcciones convergentes. De un lado, enfatizarán el valor social de los bienes extraeconómicos o postmaterialistas tales como la ecología y la paz; de otro lado, expandirán el concepto y la práctica de la democracia en orden a incorporar la participación directa o la democracia de base. El éxito de la lucha por bienes extraeconómicos estará condicionado por el éxito de la lucha por bienes económicos y por una distribución de recursos más justa. La lucha por la democracia participativa evitará la castración de la democracia representativa. Sólo en este sentido pueden ser defendidas las promesas de la modernidad, de ahora en adelante, en términos postmodernos. La comprensión postmoderna de las leyes comienza en este punto. Me centraré en los tópicos que, desde mi punto de vista, serán más cruciales en la construcción de un nuevo sentido común jurídico. 


\section{El fin de los monopolios de la legalidad}

El movimiento hacia una comprensión postmoderna del derecho comienza en los sesenta con los estudios del pluralismo jurídico en sociedades complejas seguidos por la atención a la justicia informal. Es posible rastrear las exigencias teóricas y normativas que hay detrás de estos estudios, en los debates que tienen lugar en la filosofía jurídica del siglo XIX, sin embargo, son nuevas en la medida en que están basadas sociológicamente e informadas por una postura progresiva. Estos estudios también fueron una parte del paradigma sociológico-jurídico dominante, esto es, el análisis crítico de la discrepancia entre el «derecho de los libros» y el «derecho en acción», con el propósito de contribuir positivamente a una mayor eficiencia en el sistema jurídico oficial.

El problema con tales estudios fue que en ellos estas dos dimensiones, la crítica y la positiva, no estaban suficientemente equilibradas. Explícita o implícitamente tales estudios contenían una crítica devastadora del sistema jurídico oficial, sin embargo, se conformaron con contribuir con algunas mejoras de menor importancia en las operaciones del sistema. Con el privilegio de adivinar podemos decir hoy que en cuanto se dirigían a los legisladores o a Estados burocráticos, estaban abocados al fracaso (Sarat y Silbey, 1987). El desencantamiento con estas cuestiones científicas, con la captación de su capacidad crítica y con las perversas consecuencias de algunas de sus propuestas, explica el sentido de fracaso. A mi entender, este fracaso podría haber sido evitado si, en lugar de dirigirse a los burócratas del Estado, hubieran presentado su agenda científica a la gente en general o a grupos sociales específicos (esto es, diferentes orientaciones del discurso jurídico) y hubieran tratado de generar en ellos un nuevo sentido común jurídico. El genuino fragmento de contenido utópico de tales estudios radicaba en la verificación de que en el mismo espacio geopolítico no hay sólo uno sino diferentes órdenes jurídicos y que, en consecuencia, la exigencia del Estado de monopolizar la producción del derecho era absurda. En cuanto somos una red de subjetividades y entramos en relaciones sociales en las que están presentes diferentes combinaciones de formas de poder, también vivimos en órdenes jurídicos y comunidades jurídicas diferentes y solapados. Cada uno de ellos opera en un espacio social privilegiado y tiene una dinámica temporal específica. En cuanto los espacios sociales interpenetran y los diferentes órdenes jurídicos no son sincrónicos, el particular almacena significados jurídicos que activamos en contextos prácticos 
concretos que a menudo son complejas mezclas no sólo de diferentes concepciones de la legalidad, sino también de generaciones de normas diferentes, unas viejas, otras nuevas, unas declinan y otras emergen, algunas propias y otras importadas, algunas testimoniales y otras impuestas.

Podemos identificar cuatro formas básicas de derecho que se encuentran en la sociedad y se corresponden con las cuatro subjetividades básicas y las formas de poder: el derecho doméstico, el derecho nativo de la familia; el derecho de producción que incluye los códigos de las empresas y las regulaciones internas de las corporaciones; el derecho territorial, que es el derecho en el sentido convencional y oficial; y, finalmente, el derecho sistémico que regula las relaciones entre los Estados-naciones y que se extiende más allá del dominio del derecho internacional (Santos, 1985: 309). Existen otros órdenes legales pero éstos son los órdenes básicos que estructuran las formas en las que los otros operan. Este control disperso de los órdenes jurídicos tiene dos importantes implicaciones para la comprensión postmoderna del derecho: primera, de las cuatro formas del derecho, sólo una, el derecho territorial, es democrático incluso si no es totalmente así. El contenido democrático de esta forma de derecho sólo puede expandirse o incluso meramente asegurarse si la democratización de las otras formas de derecho ocupa un lugar central en las agendas políticas de la participación. Segundo, relativizado de esta forma, el derecho en general y de modo más particular el derecho del Estado es trivializado y descanonizado (y, consecuentemente, la distinción entre high law y low law tiende a desaparecer). El valor social emancipatorio de un orden jurídico dado reside en su capacidad para asegurar y extender los derechos colectivos e individuales (en última instancia, los derechos son formas de competencia social). La comprensión moderna del derecho sacralizaba el derecho y trivializaba los derechos. La comprensión postmoderna del derecho trivializa éste y sacraliza los derechos.

\section{Del modelado a la repetición:}

hacia un nuevo minimalismo jurídico

El derecho del Estado moderno ha experimentado algunos cambios en los tres períodos de desarrollo del capitalismo. En el primer período, los desarrollos jurídicos más importantes se dirigían a extender y consolidar el principio del mercado. En el período del capitalismo organizado, el derecho del Estado se caracterizó 
específicamente por la consolidación y expansión del principio del Estado y del principio de la comunidad. En el período actual del capitalismo desorganizado, en un nivel superficial, parece que las tendencias se desplazan respecto del período previo, para continuar imperturbadas. Sin embargo, en un nivel más profundo, han tenido lugar algunos cambios importantes, que resumiré como la supresión relativa del valor simbólico del derecho, que tiene lugar en la transición del derecho máximo al derecho mínimo.

El derecho del Estado moderno fue un derecho máximo en el primer período e incluso más en el segundo. La construcción política del reformismo legal como modo hegemónico de transformación social dotó al derecho del Estado con poderes imperialistas que fueron utilizados para declarar la muerte de un doble enemigo: la revolución social de un lado, y todos los tipos de derecho popular, derecho que no es del Estado, derecho no oficial, de otro. Los rituales desaparecidos fueron realizados de diferentes formas y en diferentes períodos. Fuera de ellos emergió el derecho del Estado como un derecho único, autónomo y dotado de una especie de aura. El aura, que como en el arte moderno se inscribió desde el principio en su singularidad, fue ampliada posteriormente por el prestigio de la ciencia jurídica, especialmente en Europa continental y por el poder social de las facultades de derecho en Europa y en Norteamérica. Al derecho del Estado moderno, fijado en las sólidas esculturas de los códigos de derecho, las decisiones de los altos tribunales, orientando artículos en las revistas científicas, se le permitió verificar el slogan de Comte de «orden y progreso» y planificar el futuro, unas veces como repetición del presente, y otras modelando y controlando la innovación social. Apoyándose en la persistencia de sus construcciones materiales, el derecho del Estado moderno, como el arte moderno, adoptó una apariencia estética en la dinámica de un eterno presente contrastada con el efímero pasado y el futuro trivial.

En los últimos años han ocurrido dos cambios complementarios que han socavado el pedestal sobre el que se situaba esta postura legal. En primer lugar, el crecimiento del Estado regulador y la gran velocidad de la repetición y modelística jurídicas conducen a una creciente obsolescencia del derecho del Estado. Su sólida inmovilidad parece haberse desvanecido como si estuviera poseído, como las imágenes televisivas, por una estética de la desaparición más que por una estética de la aparición. En segundo lugar, tanto en el nivel más bajo del Estado como en el más elevado han aparecido formas de derecho que son explícitamente 
líquidas, efímeras, incluso negociables y renegociables, en suma, disponibles. Entre los muchos ejemplos, voy a citar dos, uno en el nivel del infra Estado, el otro al nivel del supra Estado. Son, respectivamente, la regulación de las subcontrataciones, es decir, las leyes especiales y contratos que regulan las relaciones de producción entre corporaciones (Marqués, 1987), y la legislación de la Comunidad Económica Europea (Snyder, 1987). De diferente forma, ambos ejemplos atestiguan la aparición de una legalidad contextual, sutilmente dirigida a los intereses momentáneos de las partes implicadas y a las relaciones de poder entre ellas. Para que estas formas de derecho emerjan, el hic et nunc se convierte en un imperativo categórico. La hiperproductividad del contexto social no sólo es tolerada sino también celebrada. Como alguna corriente del arte postmoderno americano, los «nuevos objetivistas» que he mencionado con anterioridad, esta legalidad postmoderna «reduce deliberadamente el nivel de su propia atmósfera tradicional en orden a restablecerla para una función adaptada a los tiempos» (Oliva, 1988: 66). Es un derecho antinatural, intersticial, casi un derecho coloquial, que repite las relaciones sociales en lugar de modelarlas, y de tal forma, que la distinción entre el conocimiento jurídico profesional y no profesional tanto como la discrepancia entre el «derecho de los libros» y el «derecho en acción» deja de tener sentido.

Frente a este nuevo minimalismo jurídico, el sociólogo del derecho se esfuerza por identificar y aislar la dimensión jurídica de las relaciones sociales, una situación que recuerda a los antropólogos del derecho respecto a las llamadas sociedades primitivas. Los libros reales del derecho son cada vez más las imágenes cambiantes de las relaciones sociales. Pero esto explica por qué la situación de los sociólogos del derecho es, en efecto, tan diferente de la de los antropólogos del derecho. El nuevo minimalismo sólo es posible sobre la base de una tradición preexistente de un derecho dotado de aura, autónomo y altamente profesionalizado, ciertamente, el derecho mínimo se desarrolla a menudo por profesionales formados en la tradición del derecho maximalista. La hiperproductividad del contexto social es un fenómeno complejo porque este último se encuentra en gran medida saturado por la legalidad moderna y ha sido modelado por ella. En otras palabras, la contextualización de la legalidad posmoderna es un proceso de dos vías: la de la aproximación del derecho a la realidad social y la aproximación de la realidad social al derecho.

Esta emergente y por ahora todavía marginal legalidad posmoderna 
coexiste pacíficamente con la legalidad moderna, pero en la medida en que le gana terreno corroe la posición simbólica de legalidad moderna, al forzarla a descender a la materialidad del hic et nunc. Lentamente pero con firmeza, el derecho moderno transita desde la modelación a la repetición, desde la duración de la copresencia, y de forma concomitante, de la generalidad al particularismo, desde la abstracción a la rematerialización.

\section{Derecho, microrrevoluciones y neoludismo}

La transición de la modelación a la repetición, de la planificación a la ratificación, no significa que el derecho vaya a desaparecer completamente en las relaciones sociales que regula. El derecho seguirá realizando una intensa función a través de la cual las relaciones sociales son desviadas de una cadena ordinaria de seres hacia una cadena más elevada. La diferencia se encontrará en los modos a través de los cuales tales funciones serán realizadas. En cuanto el derecho, por medio de sus principales operadores, alcanza a comprender que su falsa utopía está llegando a un final, el mundo tal como es se hará más reconocible en el proceso de su intensificación jurídica legal. En la medida en que esto ocurra, tendrán lugar dos fenómenos relacionados: de un lado, los límites de las transformaciones sociales se harán más patentes a través del derecho; de otro lado, otras formas de prácticas emancipatorias ganarán o recuperarán la credibilidad social.

De entre los límites del derecho y del reformismo jurídico, nos referiremos a los que serán importantes. En primer lugar, el derecho del Estado es una entre algunas formas de derecho que tienen lugar en sociedad, aun cuando sea la más importante. Ciertamente, se ha convertido cada vez en más importante en el período del capitalismo organizado, pues los objetivos y estrategias del reformismo y la democratización se concentraron en el derecho del Estado. En este proceso, todas las demás formas de derecho existentes en la sociedad fueron dejadas fuera del marco jurídico y así se les permitió que continuaran reproduciendo status quo y relaciones sociales no democráticas. En cuanto se expone este proceso de reducción y ocultación, se descubre la naturaleza no democrática del derecho como conjunto e incluso se pone en cuestión el contenido democrático del derecho del Estado. Pues el derecho del Estado, mientras regula relaciones sociales, se ve forzado a interactuar y negociar con otras formas de 
derecho y sus exigencias reformistas y democráticas deben ser contextualizadas y relativizadas, especialmente en virtud de la hiperproductividad del contexto social diagnosticada más arriba. Podemos encontrar una reciente ilustración de este proceso en el brillante análisis de Kristin Bumiller sobre las formas en que las leyes contra la discriminación han contribuido, de hecho, a perpetuar el carácter de víctimas de la gente a la que trataban de ayudar (Bumiller, 1988).

El segundo límite del derecho y el reformismo jurídico es que el auténtico reformismo jurídico es difícil de realizar y que, cualquier realización, no mantiene su significado social durante mucho tiempo. Asumiendo que el contenido no democrático de una red de órdenes jurídicas dadas se expone socialmente, esta exposición contribuirá por sí misma a aumentar el poder de aquellos grupos sociales que han sido las mayores víctimas de la primera ocultación. Cuanto más justa sea la distribución de recursos de poder entre grupos interesados en las reformas jurídicas, más duras serán las negociaciones para producir leyes reformistas y más estrecho el objetivo de las reformas. En consecuencia, las leyes se harán más particularistas y más complejas. La idea de la pérdida de complejidad del orden social por medio del derecho, que Weber y Luhmann de forma más visible celebraron como el genio derecho moderno (Luhmann, 1969), llegará a un final, final que en sí mismo no es algo malo. Sin embargo, contribuirá, con carácter definitivo, a descanonizar y trivializar el derecho general y el derecho del Estado, en particular. Probablemente, estos efectos se intensificarán por el contraste e incluso la fuerte presión en los acuerdos regulativos renegociados o en las imposiciones, en una época de velocidad audiovisual y de aceleración social. En estas circunstancias, el derecho puede encontrarse fácilmente en un dilema: ni permanecer estático e ignorado, ni rezagarse con respecto a la dinámica social y, por tanto, devaluarse como referencia normativa.

El tercer límite del derecho del Estado moderno se encuentra en la necesidad que éste tiene de disponer de la escala (en términos cartográficos) que el derecho utiliza para representar y distorsionar la realidad social. Ya he tratado este tópico en otro lugar (Santos, 1987b). En este momento será suficiente mencionar que la escala específica utilizada para representar la realidad 
explica el tipo de fenómenos que pueden y cuáles no pueden ser regulados adecuadamente por el derecho. Existen fenómenos, independientemente de su importancia en términos sociales, que no pueden ser tratados adecuadamente por el derecho, ya que su regulación cae fuera del umbral definido por la escala en la que opera un derecho particular. Por dar algunos ejemplos, vivimos en el mundo de Chernobyl y el SIDA. A pesar de su seriedad, parece que el derecho del Estado no puede tratar ninguno de estos problemas adecuadamente, uno porque es demasiado público o demasiado colectivo (Chernobyl), el segundo porque es excesivamente privado o demasiado individual (SIDA). En estos tipos de límites aparece identificada con mayor facilidad una cuestión que surge inevitablemente: si el derecho no puede tratar adecuadamente algunos de nuestros problemas más serios, ¿por qué seguimos tratándolo nosotros tan seriamente?

El principio de reconocimiento del mundo que inspira la comprensión postmoderna del derecho no está confinado a una función negativa de identificación de los límites del derecho. Fomenta nuevas situaciones positivas. De un lado, la identificación de límites traza un mapa de espacios sociales en los que, por contraste, tienen lugar prácticas emancipatorias que no son jurídicas (ilegales o alegales). De otro lado, en la medida en que la identificación de límites va pareja a la expansión del concepto de derecho y de su fragmentación interna en una pluralidad de órdenes jurídicos, la exigencia ideológica del fetichismo legal se hace más insostenible y las alternativas a ello, consecuentemente, más creíbles. Podemos resumir estas alternativas en los conceptos de microrrevoluciones y neoludismo.

$\mathrm{Si}$ analizamos atentamente el debate reforma/revolución en este siglo, podemos concluir que el debate giró en torno a diferentes estrategias para realizar el mismo objetivo básicamente, esto es, el socialismo. Cuando el reformismo obtuvo la primacía de la transformación social, para que se produjera en su nombre, fue reducido a escala gradualmente y el derecho del Estado fue el instrumento utilizado para realizar tal objetivo. Puede argumentarse también, en favor de la relativa autonomía del derecho, que el derecho reconstruyó la escala de la transformación social a un nivel que maximizaría la eficacia de la regulación jurídica. Desde entonces se produjo una discrepancia entre la escala del reformismo legal y la escala mucho mayor de la revolución, una discrepancia que fomentó el descrédito de la revolución ${ }^{14}$. Esto no creó serios problemas en las sociedades capitalistas avanzadas, en tanto el reformismo jurídico se mantuvo intacto en su hegemonía ideológica. Sin embargo, en los últimos

${ }^{14}$ Hablo de revolución social a gran escala en consideración a la inteligibilidad. En términos de técnica cartográfica se podría hablar, en este caso, de pequeña escala: cuanto mayor es el espacio real que ha de ser representado en el espacio limitado de los mapas, menor es la escala. Vid. Santos (1987b: 283) 
años la situación ha cambiado, como antes he señalado. La supresión gradual del aura simbólica del derecho va a abrir un vacío en nuestra imaginación social. Tras un siglo de reformas a pequeña escala es imposible, sin embargo, llenar este vacío con el viejo concepto de revolución social a gran escala. Una revolución social posrreformista sólo puede ser un entretejido de microrrevoluciones que tengan lugar localmente en las comunidades políticas, cuantas veces y allí donde se creen.

Tratar de conceptualizar tales microrrevoluciones no es tarea fácil. Puede ayudarnos la vía de proceder por sectores -ciertamente una forma muy postmoderna- y tratar de recuperar, reciclar y reinventar formas degradadas de resistencia social frente a la opresión. Así, el concepto de neoludismo, que evoca la destrucción de telares mecánicos en las primeras décadas del siglo XIX por los trabajadores ingleses, enfrentados a la introducción de nuevas tecnologías que eliminarían su autonomía en el proceso de trabajo y agravaría aún más sus ya lamentables condiciones de trabajo. Durante algunas décadas, tales estallidos de protesta fueron rechazados como locos, románticos y de resistencia reaccionaria frente al progreso inevitable. Más recientemente, sin embargo, y no por mera coincidencia, los movimientos luditas han sido reconsiderados. El trabajo pionero de Eric Hobsbawn (1964) seguido de otros (Wasserstrom, 1987), han contribuido al cambio del símbolo ludita para convertirlo en la única acción racional colectiva asequible a los trabajadores antes de la época de la sindicación. Lo que está apareciendo en la agenda política no son los medios específicos de resistencia utilizados por los luditas sino más bien la invención de formas de innovación social que como aquellas de los luditas confirman e intensifican la capacidad de subjetividades autónomas para liberarse a sí mismas de los prejuicios del fetichismo legal.

En la era tecnológica, el neoludismo será, ciertamente, menos violento e ingenuo pero tendrá que ser testigo igualmente de la intensidad del compromiso político y la movilización política, sólo accesibles cuando los objetivos de la lucha son transparentes y los resultados tengan expectativas de realización, y sean esperados tan pronto como sea posible en el mundo de la vida cotidiana. Sólo bajo estas condiciones podrá vivirse la lucha como racional de una minirracionalidad que sólo es total en la medida en que sea local. Las comunidades interpretativas y transformadoras generarán estas luchas a través de procesos de persuasión retórica que encontrarán su bagaje argumentativo en los tópicos que puedan ser extraídos de los guiones de historias parciales sobre el conocimiento, deseo y capacidad a los que me 
he referido anteriormente. El problema no es si tales minirracionalidades tienen poco peso, si son racionalidades portátiles o de bolsillo, con tal de que explosionen en nuestros bolsillos.

(Trad. de María José Añón Roig)

\section{BIBLIOGRAFÍA}

Adorno, Th. W. (1981), Äesthetische Theorie, Frankfurt, Suhrkamp.

Apel, Karl-Otto (1984), «The Situation of Humanity as an Ethical Problem», Praxis International, 4, 250.

Arendt, Hannah (1963), Between Past and Future, Cleveland, Meridian Books.

Auerbach, Erich (1968), Mimesis. The Representation of Reality in Western Literature, Princeton, Princeton University Press.

Bachelard, Gaston (1971), Le Nouvel Esprit Scientific, Paris, P.U.F.

- (1972), La Formation de l'Esprit Scientific, Paris, J. Vrin.

Bateson, G. (1985), Mind and Nature, London, Fontana.

Billet, L. (1975), «Political Order and Economic Development: Reflections on Adam Smith's Wealth of Nations», Political Studies, 23, 430.

Bloom, Harol (1973), The Anxiety of Influence, New York, Oxford University Press.

- (1988), Poetics of Influence, New Haven, Henry R. Schwab.

Bohm, David (1984), Wholeness and the Implicate Order, London, Ark Paperbacks.

Boulding, Kenneth (1964), The Meaning of the Twentieth Century, London, Allen and Unwin.

Briggs, J. and F. D. Peat (1985), Looking Glass Universe. The Emerging Science of Wholeness, London, Fontana.

Brunkhorst, Hauke (1987), «Romanticism and Cultural Criticism», Praxis International, 6, 397.

Bumiller, Kristin (1988), The Civil Rights Society, Baltimore, Johns Hopkins University Press.

Bürger, Peter (1984), Theory of the Avant-Garde, Manchester, Manchester University Press.

Capra, F. (1976), The Tao of Physics, New York, Bantam Books.

(1979), «Quark physics without quarks: A review of recent developments in S-matrix theory», American Journal of Physics, 47, 11. (1983), The Turning Point, New York, Bantam Books.

Chew, G. (1968), «Bootstrap: a Scientific Idea?», Science, 161, 762.

- (1970), «Hard-on Bootstrap Triumph or Frustration?», Physics Today, 23, 23.

Dallmayr, Fred (1987), «Public or Private Freedom? Response to Kateb», Social Research, 54, 617.

Dicey, A. V. (1948), Law and Public Opinion in England, London, MacMillan.

Durkheim, Emile (1964), The Division of Labor in Society, New York, Free Press. 
Eigen, M. and P. Schuster (1979), The Hypercycle: a Principle of Natural Self-Organization, Heidelberg, Springer.

Feyerabend, Paul (1978), Against Method, London, New Left Books.

- (1981), Realism, rationalism and Scientific Method, Cambridge, Cambridge University Press. (1985), Science in a Free Society, London Verso.

Gadamer, H. G. (1965), Wahrheit und Methode, 2nd ed. Tubingen, J. C. B. Mohr.

- (1983), Reason in the Age of Science, Cambridge, Mass., M. I. T. Press.

Gellner, Ernest (1986), Relativism and the Social Sciences, London, Cambridge University Press.

- (1987), Culture, Identity and Politics, Cambridge, Cambridge University Press.

Gouldner, Alvin (1970), The Coming Crisis of Western Sociology, New York, Avon.

Habermas, Jürgen (1973), Legitimationsprobleme im Spätkapitalismus, Frankfurt, Suhrkamp.

— (1985), Der Philosophische Diskurs der Moderne, 2nd edition, Frankfurt, Suhrkamp.

Haken, H. (1977), Synergetics: An Introduction, Heidelberg, Springer.

(1985), «Synergetics-An Interdisciplinary Approach to Phenomena of Self-Organization», Geoforum, 16, 205.

Hassan, Thab (1987), The Postmodern Turn, Ohio, Ohio State University Press.

Heisenberg, W. (1971), Physics and Beyond, London, Allen and Unwin.

Heller, Agnès (1987), «The Human Condition», Thesis Eleven, 16, 4.

Hilferding, Rudolf(1981), Finance Capital: a Study of the Latest Phase of Capitalist Development, London, Routhledge and Kegan Paul.

Hobsbawm, Eric (1964), Labouring Men, New York, Weidenfeld and Nicolson.

Huyssen, Andreas (1986), After the Great Divide, Bloomington, Indiana University Press.

James, William (1969), Pragmatism, Cleveland, Meridian Books.

Jantsch, E. (ed.) (1981), The Evolutionary Vision, Boulder, Westview Press.

Jay, Martin (1985), «Habermas and Modernism», in R. Bernstein (ed.), Habermas and Modernity, Oxford, Polity Press, 125.

Jones, R. (1982), Physics as Metaphor, New York, New American Library.

Kateb, George (1987), «Death and Politics: Hannah Arendt's Reflections on the American Constitution», Social Research, 54, 605.

Kelsen, Hans (1967), The Pure Theory of Law, Los Angeles, University of California Press.

Koyré, A. (1986), Estudios Galilaicos, Lisboa, D. Quixote.

Kuhn, T. (1970), The Structure of Scientific Revolutions, 2nd ed., Chicago, University of Chicago Press.

Laclau, Ernesto and C. Mouffe (1985), Hegemony and Socialist Strategy. Towards a Radical Democratic Politics, London, Verso.

Ladrière, J. (1967), «Les Limites de la Formalization», in Piaget (1967: 312).

Lash, Scott and John Urry (1987), The End of Organized Capitalism, Oxford, Polity Press.

Luhmann, Niklas (1969), Legitimation durch Verfahren, Darmstadt, Luchterhand.

Marques, Maria M. (1987), «A Empresa, o Espaço e o Direito», Revista Crítica de Ciências Sociais, $22,69$. 
Luckacs, Georg (1972), Studies in European Realism, London, Merlin Press.

Maturana, H. R. and F. J. Varela (1973), De máquinas y seres vivos, Santiago de Chile, Editorial Universitaria.

(1975), Autopoietic Systems, Urbana, Biological Computer Laboratory University of Illinois.

Merton, Robert (1968), Social Theory and Social Structure, New York, Free Press.

Morin, Edgar (1982), Science avec Conscience, Paris, Fayard.

Moscovici, Serge (1985), The Age of the Crowd, Cambridge, Cambridge University Press.

Mouzelis, Nicos (1988), «Marxism or Post-Marxism», New Left Review, 167, 107.

Offe, Claus (1985), Disorganized Capitalism, Oxford, Polity Press.

- (1987) «The Utopia of the Zero-Option. Modernity and Modernization as Normative Political Criteria», Praxis International, $7,1$.

Oliva, A. Bonito (1988), «Neo-America», Flash Art, 138, 62.

Ong, Walter (1982), Orality and Literacy, London, Methuen.

Parain-Vial, J. (1983), Philosophie des Sciences de la Nature. Tendances Nouvelles, Paris,

Klincksieck.

Perelman, Chaim(1971), The New Rhetoric. A Treatise on Argumentation, Indiana, Indiana University Press.

Piaget, J. (ed.) (1967), Logique et Connaissance Scientifique, Paris, Gallimard.

Prigogine, I. and I. Stengers (1979), La Nouvelle Alliance. Metamorphose de la Science, Paris, Gallimard.

Prigogine, I. (1980), From Being to Becoming, S. Francisco, Freeman. (1981), «Time, Irreversibility and Ramdomness», in E. Jantsch (1981: 73).

Radnoti, Sandor (1987), «A Critical Theory of Communication: Agnes Heller's Confession to Philosophy», Thesis Eleven, 16, 104.

Reichenbach, H. (1970), From Copernicus to Einstein, New York, Dover Publications.

Rorty, Richard (1980), Philosophy and the Mirror of Nature, Princeton, Princeton University Press.

Rousseau, Jean-Jacques (1971), Oeuvres Complètes, vol. 2, Paris, Seuil.

Saint-Simon, Henri (1975), Henri Saint-Simon(1760-1825). Selected Writings on Science, Industry and Social Organization (edited by K. Taylor), London, Croom Helm. (1977), Oeuvres, vol. 2, Geneva, Slatkine Reprints.

Santos, Boaventura de Sousa (1985), «On modes of Production of Law and Social Power», International Journal of Sociology of Law, 13, 299. (1987a), Um Discurso sobre as Ciências, Porto, Afrontamento.

(1987b), «Law: a Map of Misreading. Toward a Postmodern Conception of Law», Journal of Law and Society, 14, 279.

Sarat, Austin and Susan Silbey (1987), «The Pull of the Policy Audience», Unpublished Manuscript, September 1.

Schulte-Sasse, Jochen (1984), «Foreword: Theory of Modernism versus Theory of the Avant-Garde», in Bürger (1984).

Snyder, Francis (1987), «New Directions in European Community Law», Journal of Law and Society, $14,167$.

Sontag, Susan (1987), «The Pleasure of the Image», Art in America, November, 122.

Swingewood, Alan (1975), The Novel and Revolution, London, MacMillan.

Thom, René (1985), Parábolas e Catástrofes, Lisboa, D. Quixote. 
Viner, Jacob (1927), «Adam Smith and Laisse-Faire», The Journal of Political Economy, 35, 198. Virilio, Paul (1988), «Interview with Paul Virilio», Flash Art, 138, 57.

Wasserstrom, Jeffrey (1987), «Civilization and its Discontents. The Boxers and Luddites as Heroes and Villains», Theory and Society, 16, 675.

Winckler, H. A. (ed.) (1974), Organizierter Kapitalismus: Voraussetzungen und Anfänge, Göttingen, Vandenhoeck and Ruprecht.

\section{AGRADECIMIENTOS}

En marzo de 1987 di una conferencia sobre una primera versión de este trabajo en el Ameherst College. Quiero agradecer a los colegas del seminario de Amherst su invitación, su estimulante respuesta y, sobre todo, el hecho de haber compartido conmigo la seductora atmósfera de su comunidad científica. Quisiera agradecer también a María Irene Ramalho, Simon Roberts, Nicos Mouzelis, Tim Murphy, David Trubek, Ronald Chilcote y Steward Macaulay sus comentarios sobre las primeras versiones de este trabajo. 